\title{
EL CONTROL ESTATAL DE LA HACIENDA MUNICIPAL ALICANTINA EN EL SETECIENTOS *
}

\author{
Por Candelaria SAIZ PASTOR \\ Universidad de Alicante
}

(*) El presente artículo puntualiza algunas ideas contenidas en la reciente memoria de licenciatura que presenté en la Universidad de Alicante, bajo la dirección de Enrique Giménez López, con el título Abastecimiento y Hacienda Municipal en el Alicante del siglo XVIII. Facultad de Filosofía y Letras. Noviembre, 1982.

Tradicionalmente, el siglo XVIII ha sido calificado como el «siglo de las reformas». Apuntar sucintamente que la eclosión reformista no surgió de repente en el panorama español, sino que tenía sus raíces y continuidad en los dos siglos anteriores a la Edad Moderna, supone, en cierto modo, afirmar que el auge reformador dieciochesco - considerado por algunos como aporte innovador de la dinastía borbónica - se planteará desde otra perspectiva y se desarrollará hasta sus últimas consecuencias en el Setecientos: robusteciendo la centralización y la uniformidad del Estado. En efecto, la corriente arbitrista anterior que había proclamado que todos los reinos de la Monarquía contribuyeran de igual manera con las cargas impositivas para mantener el Imperio, junto al proyecto práctico de centralización administrativa ensayado por Olivares, se erigen en importantes precedentes que hacen corroborar esta tesis. Sin embargo, una vez 
fracasados los intentos del Conde-Duque, la política intervencionista de la Corona de los Habsburgo se cifró, una vez más, en la existente realidad institucional que no favorecía la consolidación del progreso de la centralización. Prueba de ello lo constituye el reinado del último Austria, que ha sido calificado por Joan Reglá de «neoforalista».

Las circunstancias provocadas después de la victoria incondicional de las armas borbónicas en nuestro suelo favorecian los intereses de la Monarquía, que trasplantó a los reinos foralistas, con algunos retoques, el modelo institucional castellano aboliendo, de esta forma, todo el marco institucional vigente que habia tenido su origen y esplendor en el Medievo. Era, pues, el momento propicio para tomar una serie de medidas tendentes a reorganizar la Hacienda Real e incrementar sus ingresos. En los antiguos reinos de la Corona de Aragón, el comienzo de la práctica de la reforma financiera - conducente a ampliar los ingresos del tesoro real-, el traspaso de las instituciones castellanas y la mengua de privilegios irán conformando un lento proceso en el que el Estado tenderá a centralizar y, por ende, a controlar la relativa autonomía financiera de estos territorios.

No hay que dejar de señalar que el municipio se muestra como un ente autónomo y no integrado adecuadamente en lo que entendemos como articulación moderna del Estado. Cada variedad local -en general, cada villa o ciudad tenia su propio código municipal y sus estatutos - figura en la raíz de esta idea. El tradicional y teórico antagonismo entre autonomía concejil y Estado Absoluto pasará a ocupar un perfil distinto en la centuria setecentista. Ahora más que nunca, los principios constitutivos absolutistas emprenderán la trayectoria de mermar la fortaleza institucional de los Ayuntamientos.

En definitiva, el intento de la Corona por controlar las rentas, propios y arbitrios locales, se plasma en la idea de minimizar el obstáculo que las ciudades podian suponer para el Estado. Obstáculo éste que tenía su razón dé ser en los privilegios financieros del Concejo. La propensión de las ciudades a recaudar pesados impuestos y gravámenes - para reembolsar sus propias deudas o contraer otras - dificultaba, a la larga, la recaudación de los dineros reales, por estar sujeta la población a múltiple fiscalidad, y se erigía en uno de los principales motivos de revisión estatal.

Entramos, pues, de lleno en uno de los campos menos atendidos, como son las haciendas locales. Para valorar ampliamente cuál fue la acción estatal sobre este aspecto, hemos elegido como área de experimentación una localidad determinada como Alicante. No obstante, tan sólo analizaremos, a grandes rasgos, las líneas centrales de su organización municipalfiscal en el Setecientos y dejaremos de lado aquellos puntos más secundarios (que no por ello menos relevantes) que no son objeto del presente artículo. 
Los aspectos más sobresalientes de la hacienda municipal alicantina se traducen, como casi en todos los patrones municipales, en las atribuciones concejiles en materia de propios y arbitrios, dos de los puntos principales para el desenvolvimiento de los pueblos en el Antiguo Régimen. Si nos hemos marcado como objetivo dilucidar la intromisión estatal en este contexto, será preciso acometer, aunque de forma somera, el análisis de los propios y arbitrios más importantes de la ciudad; planteamiento éste obligado a la hora de limitar su importancia para la Corporación y comprobar hasta qué punto fueron recortadas (o más bien reformadas) sus atribuciones.

1. Los propios de la ciudad. Los huertos de Valladolid y Cabanes.

Los municipios valencianos, en general, y el municipio alicantino, en particular, adolecian de lo que entendemos como propios; no obstante, la ciudad poseía al comienzo de la centuria dos huertas propias denominadas heredades de Valladolid y Cabanes. Su localización se centra en las tierras de regadío del término. Dotadas de agua propia, parte de ella era consumida en su riego y la restante, mediante un conducto, proveía a las fuentes de la urbe y sus arrabales(1).

Para el aprovechamiento de estas tierras con el objeto de obtener rentas, el Ayuntamiento utilizó la alternativa de su explotación indirecta mediante la forma de arrendamiento. El arriendo se adjudicaba en pública subasta al alza, en la que el aspirante o aspirantes a arrendatario pujaban sobre la cantidad anual que debía satisfacerse al Cabildo. Pero, al mismo tiempo, se exigía deltitular el pago del alfarraz. Una vez finalizado el contrato, que no solía sobrepasar de los cuatro años, la ciudad nombraba a peritos labradores que reconocian y justipreciaban el alfarraz, esto es, la cosecha existente en los huertos; el anterior arrendatario debia dejar el correspondiente al importe de un año de arrendamiento, mientras que el nuevo titular se comprometía a pagarlo(2). Con ello, la Municipalidad obtenia ganancia por partida doble, ya que no sólo cobraba la renta estipulada en el contrato, sino que se reservaba, indistintamente, el pago en metálico de una parte de la cosecha que pertenecía al arrendatario.

Las rentas que obtenía la Corporación de este arrendamiento no eran muy sustanciosas. Para abordar en su justa dimensión esta afirmación, es preciso consignar un hecho: las cantidades rematadas en las subastas no ascienden, en el mejor de los casos, a 500 libras, lo que indica en cierto modo la escasa cuantía que afluía a las arcas concejiles en razón de este concepto(3), permitiéndonos corroborar la parva incidencia que sobre los ingresos municipales tenían los denominados propios en la ciudad (4). 


\section{La fiscalidad local. Los arbitrios.}

Es bien sabido por todos que el gobierno municipal de los pueblos en el Antiguo Régimen se rige ante todo por el privilegio, uso, costumbre y ordenanzas especificas de cada uno de ellos. De esta forma, el marco de legalidad local estaba delimitado no por una ordenación unitaria, sino por el resultado de un variopinto mosaico de normas de distinto alcance y antigüedad. Todo ello posibilitaba en Alicante el disfrute de variados impuestos, garantizados por un enjambre de privilegios financieros que tenía su origen en antiguas facultades reales de la Baja Edad Media(5).

Tras la Nueva Planta, la ciudad siguió conservando una serie de ingresos peculiares constituidos por la percepción de sus arbitrios. En la medida en que las rentas de propios no cubrian, ni siquiera mínimamente, las cantidades ingresadas en el erario local, se acudía a aquel conjunto de cargas impositivas - que mediante gravámenes recargaban los precios sobre variados artículos de consumo-, del que se obtenian los mayores emolumentos. Estas cargas, de naturaleza exclusivamente local, se configuran no sólo de importancia marcadamente significativa para la Corporación, sino, y al mismo tiempo, coadyuvantes a la constitución de un tipo de mercado que restringía la libertad de comercio y constreñian, por ende, el desarrollo del capital comercial. Sin embargo, a través del sistema de arrendamiento de impuestos - método utilizado para la recaudación de estos gravámenes-, se permitía a un grupo reducido de individuos beneficiarse del estado de cosas. Parte de la complejidad impositiva del Antiguo Régimen queda materializada en este hecho, en que la falta de un aparato fiscal único y rápido se nos muestra consustancial con la naturaleza del Estado anterior a la revolución burguesa.

2.1. Las medidas de vigilancia municipal sobre los intercambios abocaban a que éstos se ajustaran a peso y medida. Las ordenanzas locales en materia de abastos obligaban a la designación de uno de los cargos más antiguos para garantizar las equivalencias: el mustassaf, que en el Setecientos se le denominará fiel almotacén.

Si bien sus atribuciones eran amplias, pues recaían en él funciones de policía -obras públicas, urbanismo, limpieza de calles, etc.-, su trabajo principal era el de inspeccionar las pesas y medidas oficiales (6), recibiendo a cambio unos emolumentos a expensas de vendedores y compradores que, aparte de hacer codiciado el puesto desde su creación en el siglo XIII, implicaba un mayor recargo sobre los precios de venta en el mercado ciudadano. Su designación había recaído enteramente entre aquellos grupos cuyo denominador común era el privilegio: en el Fuero del Rey Jaime I de Aragón, su elección se efectuaba uper els prohoms de la ciudad i per la cort". En el Privilegio del Rey Jaime II de Aragón se hacía notar la autonomía del cargo, prohibiéndose la intromisión del Justicia «en lo pertenent al ofici»(7). 
Si a finales del Seiscientos Carlos II estableció que el cargo se sorteara al año entre los jurats, tras la victoria felipista fue asumido por el Ayuntamiento borbónico recayendo en los doce regidores quienes se alternaban a razón de uno cada mes(8). El oficio dependió de la ciudad hasta que en 1739, Felipe $V$ lo enajenara para adjudicarlo al mejor postor. Se continuaba así un proceso iniciado con la abolición de los Fueros y la implantación de la Nueva Planta, que pretendía aumentar los ingresos del tesoro reak9). La adquisición vitalicia de ese empleo por Carlos León, quien pagó a la Corona 16.000 rls.(10), asestaba un fuerte golpe al municipio. No podia ser de otra forma, la posesión particular del cargo suponía una cierta independencia del control que, en materia de consumos, ejercia el Concejo; al mismo tiempo que, privaba a las autoridades de unos ingresos nada desdeñables y al margen de sus respectivos emolumentos como capitulares. Si el Monarca, mediante el sistema de tanted(11), accedió a que el Cabildo recuperara el oficio, al ordenar que éste recayera vitaliciamente en el regidor Ignacio Burgunyo(12) despojaba definitivamente a los demás munícipes de sus importantes beneficios, mermando facultades al gobierno oligárquico municipal.

Un grupo de oficios menores vinculados al almotacén - por ejercer sobre ellos una labor de supervisión- estaban, igualmente, relacionados con los pesos y medidas municipales. Estos empleos suponian la percepción de determinados derechos procedentes de una carga sobre ciertos artículos de primera necesidad. Todos estos servicios se arrendaban utilizando el sistema de pública subasta al alza, previa admisión de posturas (13). El derecho de peso y romana obtenía sus ingresos de la actividad comercial, gravando prácticamente todos los géneros que se importasen o exportasen por mar; el encargado de la media arroba de aceite y carretón cobraba diversas cantidades por medir el aceite que se introducía para el consumo de la ciudad; el arrendatario de la barchilla percibia no sólo 1 dinero por cada barchilla de granos que se vendiese en la población, sino también por todos los que se almacenasen en la alhóndiga y almacenes de particulares; por último, el beneficiario del cántaro de vino tenía como misión comprobar la medida exacta de las pipas y medias pipas fabricadas por el gremio de toneleros(14).

Todos ellos, además de constituir una fuente de ingresos para la hacienda local, se enmarcaban en las prácticas proteccionistas municipales, que debian velar por que no se cometieran fraudes en las equivalencias ni se cobraran más derechos que los estipulados por el Ayuntamiento. Era evidente que las cosas sucedian de forma distinta en la realidad. En muchos casos, los comerciantes, que estaban obligados a pesar los géneros recibidos en el muelle o sus almacenes procuraban evadirse de su pago gracias a que se les permitía no pesar los géneros de importación en la romana oficial, aunque estuviesen obligados, en cualquier caso, a pagar un sueldo por quintal(15). Otro ejemplo lo constituyen los numerosos fraudes que se cometieron con el sistema de venta de caldos a la menuda. Al no ser frecuente que se reconociera la medida de los barriles que los 
taberneros vendian y que no debía sobrepasar de cuatro cántaros, éstos no se sujetaban a la proporción que debian tener los toneles. Si el Ayuntamiento dio facultad a los consumidores para requerir del arrendatario del cántaro de vino sus servicios, en la mayoría de las ocasiones no hacian uso de esta facultad, puesto que ello llevaba implícito el pago de una carga que hacía que el precio de los caldos fuera mayor(16).

En último lugar, los pesos y medidas de hierro, también llamados pesas menores, sólo atañian a la venta al por menor de comestibles que realizaban los tenderos. Hemos creido conveniente resaltar su significación de forma separada por estar directamente relacionados con la merma de facultades municipales.

La instauración de este oficio data de 1747, consignándose en el Reglamento dictado por Fernando VI para la ciudad. La causa de su establecimiento figura claramente en el texto. En él se ordenaba a los regidores que disfrutaran tan sólo del salario asignado y prohibía tajantemente que pudieran percibir:

“... de los Pesos y Medidas, que davan a los vendedores de las cosas venàles diariamente de cada uno, quatro dineros por persona, Peso o Medida, cuya cantidad exigian desde el tiempo de Fueross(17).

Los propositos de la Monarquía no eran abolir el recargo que experimentaban los comestibles por semejantes prácticas - de igual manera los botiguers pagaban ahora al arrendatario de este derecho dos dineros cada vez que utilizaban las pesas-, sino que se dirigen por otros derroteros. En definitiva, se intenta separar a las autoridades municipales del disfrute de antiguas prácticas y privilegios específicos, derivados éstos del reglamentarismo local en materia de abastos. El anhelo se plasma, pues, de forma transparente: la pretensión de crear un cuerpo de funcionarios o burócratas que, a la larga, estarian al sevicio del Estado Absoluto.

2.2. La existencia a comienzos de la centuria de otro grupo de gravámenes que incidía de forma más directa en el encarecimiento del consumo urbano y en la configuración del mercado alicantino lo constituyen las llamadas sisas que gravaban los géneros introducidos en la ciudad.

Desde la centuria anterior, el municipio venía obteniendo sus mayores beneficios de una serie de impuestos marítimos o de aduana's sobre todos los géneros que se embarcaran o desembarcaran por el puerto. Este conjunto recibia la denominación de derechos marítimos y estaba compuesto de tres cargas: la sisa mayor o de mercaduria gravaba en un $2,5 \%$ de su valor todas las mercancías que entraran o salieran por la urbe; las restantes, el derecho nuevo y la saladura, recaían sobre ciertos artículos como jabón, esparto y pescados salados a razón del $1 \%$ (18).

Si las aspiraciones de la Corona se orientaban en sustituir el tradicional entramado fiscal de la época foral por otro de mayores rendimientos para la Hacienda Real, su actitud ante este conjunto impositivo se nos 
muestra reveladora. Los pasos previos que se dieron hasta desembocar en el despojo de los citados derechos son múltiples y variados (19). No vamos a describirlos con minuciosidad; sin embargo, es conveniente resaltar dos premisas que se nos antojan fundamentales.

De un lado, las deudas que el Cabildo tenía contraídas, materializadas, en su mayoria, en los censos, venían satisfaciéndose de lo que importaban los derechos marítimos. Los atrasos en el cobro y las quejas de los censalistas durante los primeros años del XVIII evidenciaban las numerosas corruptelas municipales, protegidas por el desorden que imperaba en la ciudad recién terminado el asedio que sufrieron los partidarios del Archiduque. Si a ello unimos las sospechas existentes de que la mayor parte del dinero recaudado no se dedicaba a su autentico fin, sino a gastos de difícil justificación, se plasmará la idea del escaso rigor administrativo de los municipios forales. La Monarquía no hizo más que aprovechar el momento propicio que se le brindaba. En agosto de 1717, Felipe $V$ ordenaba que la ciudad de Alicante cesara en la administración de sus propios marítimos, que pasarian a ser administrados por funcionarios reales.

El Monarca había actuado de acuerdo no sólo con el ideal político centralista, sino que también primó en él el anhelo económico de ingresar en el organismo regio una parte de las sustanciosas rentas que producia la aduana del puerto más floreciente del País Valenciano. En consonancia con esta idea y en el año 1736, pasaba a la Hacienda Real la mitad de lo que importaba el arriendo del cántaro de vino, la media arroba de aceite y la barchilla(20).

El municipio siguio disfrutando de otras sisas que afectaban a diferentes artículos de primera necesidad y que descansaban, lógicamente, sobre los consumidores.

En el caso de la sisa de la carne, su imposición recaía sobre todos aquellos potenciales compradores, excepto sobre los clérigos, nobles y militares; en 1747, fue suprimida por Fernando VI, al ser considerada ugravosa para el común»(21). Igualmente, las llamadas sisa del aceite, corte del atún y partidos del matadero incidían sobre los menos pudientes que se abastecian en las tiendas, ya que los que introducian mercancias para su uso particular estaban exentos de su pago.

Otros gravámenes estaban directamente relacionados con la supervisión que ejercia la Corporación sobre el comercio por menor de una localidad a otra. En este esquema cabe situar a la sisa de la puerta de tierra, que asumía en su poder el recargo de los géneros y mercaderias que se introdujesen por tierra en la ciudad. Si el impuesto dejaba libre de contribución aquellas mercancías que entraran "los vecinos hacendados que tenían valimiento para hacerlo", los verdaderos perjudicados eran los tenderos o minoristas, quienes se negaron, en muchas ocasiones, a tributar los tres dineros que debian abonar al arrendatario de la sisa (22).

Este conjunto de imposiciones fue sometido a revisión, por parte de los diputados y síndico personero del Común, en la segunda mitad del Se- 
tecientos. Las primeras acciones que emprendieron estos oficios se centraron en proponer la extinción de dichos arbitrios. Es aquí cuando se sucederán los primeros choques con los regidores, quienes, haciendo caso omiso a los intentos de oposición protagonizados por los representantes electos, resolvieron seguir en la práctica de estos recargos(23). Un año más tarde estos intentos dieron su resultado. En el nuevo Reglamento que se concedía a la ciudad en 1767, quedaban anulados.

"... los valores de la sisa del aceite, y partidos del matadero, por ser gravosos para el Común, y no ser necesario su producto.... (24).

De la misma forma quedaría disuelta definitivamente, la sisa de la puerta de tierra, cuando una real provisión de Carlos III, fechada el 11 de abril de aquel año, ordenaba su rápida extinción(25).

Cabe mencionar, no obstante, la existencia de dos significativas imposiciones relacionadas con el mundo de los intercambios, de las que el Cabildo obtenia importantes ingresos.

El período de crecimiento demográfico, agrícola y comercial -iniciado lentamente en la segunda mitad del siglo XVII e interrumpido con la Guerra de Sucesión - comienza a partir de los años treinta de la centuria. En este marco es interesante resaltar la concesión, por parte de la Corona al municipio, de dos importantes arbitrios: la saladura y la denominada sosa y barrilla.

La primera de ellas data de un real despacho fechado el 25 de junio de 1735. Esta sisa no influía en el consumo ciudadano, ya que recaía, únicamente, sobre el salazón que se extraía de la urbe con destino a los mercados castellanos a razón de 16 dineros por quintal. No pagaban esta carga las porciones de saladura que sirvieran para provisiones reales de mar o de tierra(26).

Pocos años después, la publicación de otro real despacho de 12 de junio de 1742 confería al Ayuntamiento facultad y licencia para poder usar del arbitrio de tres dineros sobre cada arroba de sosa y barrilla(27). En este momento la coyuntura alcista de la década de los cuarenta favorecía un mayor volumen de exportación de barrilla, que dependia de las buenas cosechas. La orientación fisiócrata que poco a poco se imponia en la correspondiente política económica del reformismo borbónico favoreció que el capital comercial se orientara hacia donde conseguia los beneficios más abundantes, en este caso, hacia la exportación de sosa y barrilla - cuya demanda internacional se incrementó ampliamente durante la primèra mitad del siglo XVIII, debido a la importancia creciente que tenía en Europa la fabricación de jabones - por el puerto de Alicante. Prueba de la importancia que adquirió la ciudad se plasma en que desde 1780 era el único puerto de la costa valenciana habilitado para el embarque de estos productos (28).

La presencia de comerciantes en la titularidad de ambos arrendamientos es considerable. Como el arriendo de estos impuestos estaba en función de las expectativas de beneficio y ello, a su vez, lo prefiguraba la 
coyuntura comercial, tratantes y comerciantes se disputaban su disfrute, por extraer de éste importantes ganancias en las épocas de apogeo económico(29).

La pervivencia de ambas contribuciones durante todo el siglo XVIII constituye el rasgo diferenciador respecto de las demás sisas. Tanto el arbitrio de la saladura como el impuesto de sosa y barrilla extraian sus derechos de negocios comerciales ampliamente lucrativos manipulados, en su mayoría, por comerciantes extranjeros. En el siglo XIX, libre ya el comercio de este tipo de cargas, la crisis de exportación barrillera se agudizó por el descubrimiento de una solución química artificial para la producción de sosa (30); por el contrario, el tráfico del salazón se revitalizó durante la centuria decimonónica y alcanzó gran relevancia a finales de siglo(31).

Conviene, por último, reseñar el porcentaje anual del total de los ingresos municipales y dejar constancia de lo que ello representaba para la Corporación.

PORCENTAJE ANUAL DE LOS INGRESOS LOCALES EN EL AÑO DE 1747

\begin{tabular}{|c|c|c|}
\hline & Libras valencianas & $\%$ \\
\hline 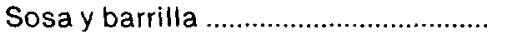 & 2.629 Is. $11 \mathrm{sl}$. & 26,72 \\
\hline 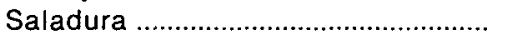 & $1.200 \mathrm{ls}$ & 10,37 \\
\hline 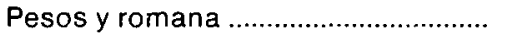 & 1.909 is. $10 \mathrm{sl}$. & 15,50 \\
\hline Sisa puerta de tierra & $1.634 \mathrm{ls} .12 \mathrm{sl}$. & 13,12 \\
\hline Sisa del aceite & 588 Is. 15 sl. & 4,08 \\
\hline Partidos del Matadero & $550 \mathrm{ls}$. & 4,50 \\
\hline Ropas, sebo y pieles ................................. & $2.120 \mathrm{ls}$ & 18,32 \\
\hline 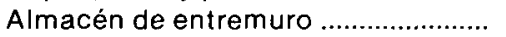 & 36 Is. & 0,31 \\
\hline Mitad del cántaro de vino, media & & \\
\hline 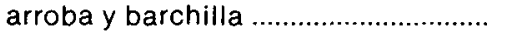 & 523 is. & 4,52 \\
\hline 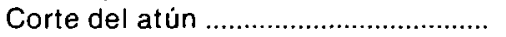 & 40 ls. $2 \mathrm{sl}$. & 0,34 \\
\hline \multirow[t]{2}{*}{ Heredad de Valladolid .............................. } & 373 ls. $7 \mathrm{sl}$. & 2,22 \\
\hline & 11.605 Is. $9 \mathrm{sl}$. & 100,00 \\
\hline
\end{tabular}

Fuente: A.M.A. Arm. 5, Lib., 62, ff. 495-510. Elaboración propia.

* En el cuadro elaborado no figura la sisa de la carne por haber sido suprimida ese mismo año. Hasta ese momento su porcentaje venía situándose alrededor del $13 \%$ del total de los ingresos. 


\section{El reformismo borbónico municipal.}

Si una de las direcciones básicas que asumió el reformismo municipal en el siglo XVIII versa en torno a la reorganización de las haciendas locales, se hace necesario interpretar las repercusiones de semejante orientación reformista en Alicante.

La esfera más enjundiosa de la administración municipal eran los capítulos correspondientes a las cantidades procedentes de los arbitrios y rentas de propios. Los privilegios financieros del municipio permitían a éste gozar de un monto particular y distribuirlo en diferentes clases en las que se detallaban la magnitud de los gastos de la Corporación. Todo ello conformaba el presupuesto local que, a más, se manejaba a antojo de capitulares, resultando, reiteradamente, la existencia de numerosas partidas en las que el dinero tenía un incierto empleo y que, por lo general, se dirigian a los llamados gastos extraordinarios de dudosa utilización.

Con el establecimiento de la nueva dinastia, la relativa autonomía financiera de que gozaban los Ayuntamientos fue decreciendo. Sin embargo, las atribuciones hacendísticas de éstos, al gozar del disfrute de sus propias rentas e impuestos, les proporcionaban un tímido autogobierno financiero defendido con celo por parte de las autoridades.

Hay que destacar que la Monarquía era perfectamente consciente del lastimoso estado en que se hallaba la administración económica de los pueblos y el grado de abusos cometidos por los regidores(32). Pero las ansias de la Corona no se centraban, únicamente, en corregir los fraudes de éstos. En el fondo de esta idea subyace el intento de transformar a los municipios en meros agentes de la Real Hacienda e integrarlos adecuadamente dentro de las coordenadas del Estado Moderno. A partir de esta premisa, conviene resaltar una serie de medidas que repercutieron en la ciudad de diferente forma.

La primera de ellas queda englobada en la órbita puramente local: la dotación a la urbe, en 1747, de nuevas ordenanzas para el «buen uso, régimen, administración y manejo de los caudales públicos», supone un inten- 
to de control estatal sobre los ingresos locales. No podemos dejar de reseñar los propósitos fundamentales de la acción borbónica que figuran escrupulosamente detallados en el texto del real decreto.

En primer lugar, las ansias uniformistas del Estado Absoluto se manifiestan de forma preclara. El monarca cree ver la causa primordial de la inoperancia de los Concejos en que éstos

"han continuado el uso de muchos de sus Fueros, y estilos antiguos, tanto en la exacción de arbitrios, como en otros puntos de su económico govierno....

y diagnostica como remedio más eficaz

"el qual no puede, no deve ser otro, que la fundamental práctica de las leyes de Castilla, deseando se establezca en las expresadas ciudades (Alicante y Orihuela) un govierno seguro....”(33).

Desde el punto de vista institucional, las innovaciones no son en este sentido abundantes. Si bien es cierto que se aspira a la unidad legislativa, tan sólo se plantea ésta, una vez más, como una mera extensión del orden castellano (34). Las novedades se concretan, sustancialmente, en dos direcciones.

De un lado, se introduce un nuevo elemento de supervisión del destino de las cantidades recaudadas en concepto de arbitrios. Hasta ese momento, el Cabildo venía satisfaciendo del caudal público el importe de muchos desembolsos que no tenian una suma fija. Ello ocurria con las fiestas, pleitos, limosnas, obras de construcción, etc., que variaban según las circunstancias, lo que provocaba la confusa aplicación del manejo de los fondos. En el nuevo Reglamento los gastos quedaban englobados en tres clases y aparecian minuciosamente expresados junto a aquellas cantidades de dinero - procedentes de los impuestos - que debían sufragarlos. (Cuadro número 2).

La primera de ellas correspondía a los salarios, los gastos ordinarios y extraordinarios. En estos últimos era donde más fraudes y malversaciones se habian cometido.

"Para gastos extraordinarios, se considera mil libras annuales, que, sin duda, son muy suficientes, respecto, de que en las antecedentes partidas, van incluídas algunas de esta especie, ademas, de haverse regulado su gasto por Quinquenios, y quedar reformadas todas las gratificaciones, Regalos, Refrescos, y otros dispendios de pura superfluidad; y para que esta partida sea bien gastada, sin que se consienta el menor exceso, ó gasto voluntarion (35). 


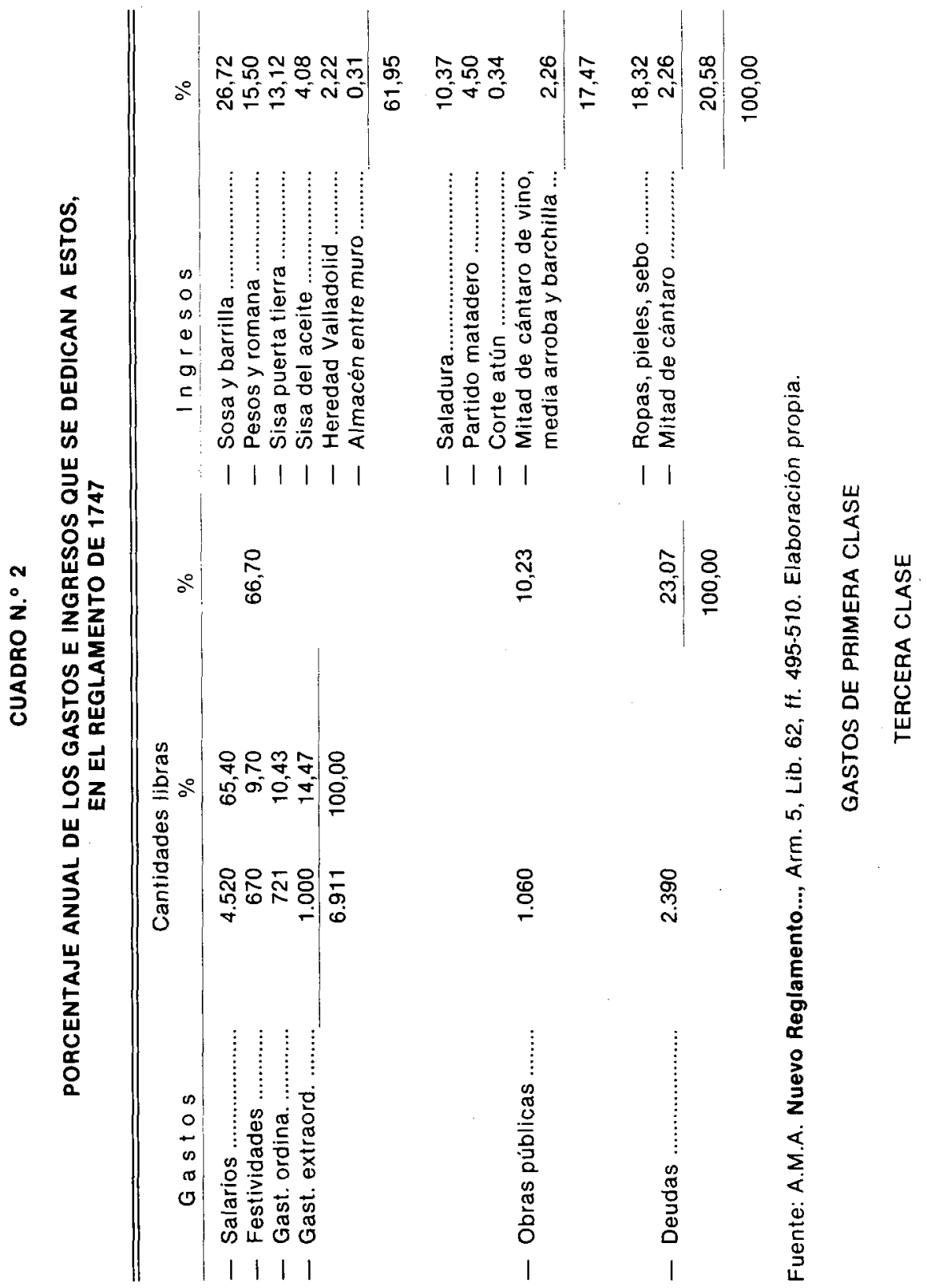


Los gastos de segunda clase abarcaban las obras y reparaciones que se efectuaban en las dos iglesias más importantes de la localidad: la Colegial de San Nicolás y la Parroquial de Santa Maria; así como en el convento de religiosas de la Santa Faz, situado en la huerta. La construcción de las nuevas casas capitulares quedaba también comprendida en esta partida, mientras que la tercera clase se dedicaba a las deudas que el Concejo tuviera contraídas. Los ingresos de la sisa de la carne - suprimida en este nuevo reglamento- irian a parar a ésta última, evaluándose en 8.000 libras (36).

De otro lado, se intenta, de igual manera, controlar de forma más directa al personal dependiente de los municipios, que si bien habia sido reformado con la legislación de la Nueva Planta seguía manteniendo una serie de atribuciones propias. Por lo que respecta a la gestión de hacienda municipal, el cargo principal correspondía al antiguo clavari, que controlaba los caudales públicos. A comienzos de la centuria este oficio se transformó en un mayordomo de propios a la manera castellana y pasaba a denominarse depositario. La Monarquía advertía el poder que podía acumular este individuo en sus manos, de ahí que definiera detenidamente sus funciones en las nuevas reglas, con las siguientes palabras:

"Este depositario ha de dàr la Cuenta del Caudal, que entrare y saliere de las arcas; y de los Recivos, y Cartas de Pago, que diere, ha de tomar razón, como también de lo que saliere, con distinción de Arcan (37).

El puesto seguía siendo uno de los más importantes, puesto que su misión principal era la de velar por la fiabilidad de las cuentas locales. No obstante, sus facultades quedaban visiblementes retocadas en 1747 . En la época foral, los arrendatarios o administradores de las rentas de propios y arbitrios podían entregar el dinero al depositario sin que estuviese presente ninguna otra persona. A partir de este momento, la entrega debía hacerse en presencia de cuatro individuos: el corregidor, un regidor diputado - previamente elegido por el Cabildo- el administrador y el depositario, quienes tenian en su poder las llaves de las tres arcas, con cuatro cerraduras cada una, donde se introducían los ingresos correspondientes a cada clase de gasto. Igualmente debía hallarse presente el escribano mayor del Ayuntamiento, ya que

"... en cada Arca, ha de haver un Libro Enquadernado, compuesto de Papèl del Sello Quarto, segun la Real Pragmatica, en todas sus ojas; el qual segun la misma, deve gastarse todo, aunque haya pasado el año, para que dicho Papèl se sellò; y el gasto de este libro, lo hà de pagàr el Arca, à que sirve» (38).

Por tanto, la responsabilidad del buen estado de las cuentas no se centraba exclusivamente en el oficio de depositario, sino que se diversifi- 
caba entre los restantes individuos cuya actuación tuviera que ver con el manejo de los fondos. Si esta medida pretendia abortar las posibles situaciones fraudulentas, ello no se consiguió del todo. En 1764, los depositarios don Joseph Paret y don Claudio Paret, fueron descubiertos en una considerable estafa. Faltaban $\mathbf{1 5 . 0 0 0}$ libras de las arcas concejiles, cantidad apreciable que había sido sustraída. La actuación de la ciudad fue pronta: se informó al Consejo de Castilla, quien resolvió se embargaran los bienes de los defraudadores y pasaran a venderse en pública subasta para asi resarcir al Ayuntamiento. Las cantidades de los embargados -justipreciadas previamente por peritos municipales- tan sólo ascendian a 10.000 libras. De nuevo fue informado el Consejo ordenando éste se procediera contra los bienes de los fiadores hasta alcanzar la cantidad restada(39).

La rápida actuación del Consejo para desenmascarar estas irregularidades viene justificada por una razón fundamental. Si se descubria esta situación podían ser acusadas la mayoría de las autoridades municipales por un fraude de este tamaño. De ahí que procedieran con la mayor prontitud para dejar bien clara su actitud de honradez fiscal delante de la Corona. No obstante, una vez desenterradas estas malversaciones, el Ayuntamiento aprovechó para colocar en este cargo a uno de los regidores del municipio: don Joseph Caturla. Un real despacho de 20 de junio de 1766 separaba del oficio al municipe por ser incompatibles ambos empleos, e instaba al Cabildo a que nombrase depositario "a sugeto idoneo" que no disfrutase de ningún cargo concejil. La ciudad no tuvo más remedio que deponer del puesto a uno de los beneficiarios del gobierno municipal(40).

La medida que venía a culminar la intervención regia en las haciendas locales, se enmarca en el periodo culminante del absolutismo monárquico, centrado en el reinado de Carlos III. La administración centralista y uniformista desarrollada por la Corona dará paso, en 1760, a una reorganización de las haciendas municipales, al pasar todos los propios del reino a ser administrados bajo la dirección de una Contaduría General de Propios y Arbitrios establecida en Madrid y de las Contadurias de las respectivas Intendencias, teniendo cada municipio su propia Junta de Propios y Arbitrios. De esta forma, se dictaban las normas que situaban al ramo bajo la estricta supervisión y dependencia del Consejo de Castilla, órgano rector de la Monarquía en el XVIII.

A comienzos del siglo, las atribuciones hacendisticas de los regidores eran amplias. Poco a poco, estos privilegios fueron mermando de distinta forma: bien directamente, atacando sus facultades financieras, como ocurre en el reglamento de 1747; bien indirectamente, aumentando, desde 1749, las facultades de los intendentes en orden a la administración de los Propios y Arbitrios locales (41). La instauración de la Junta de Propios y Arbitrios en la ciudad pretendia cercenar el control semiprivativo que los 
regidores tenían sobre los caudales públicos. Otra cosa es si verdaderamente ocurrió así.

Para ello resulta necesario hacer notar la composición de la Junta, que debía estar constituida por el corregidor, dos regidores y el depositario. En Alicante estos puestos fueron ocupados por las siguientes personas (42):

- Presidente: Don Joseph Juan Ladrón de Guevara. Teniente General de los Reales Ejércitos, Gobernador y Corregidor por Su Majestad de la ciudad de Alicante.

- Regidores: Don Juan Rovira y Torres y don Tomás Biar Juan.

- Depositario: Don Joseph Paret.

Lógicamente, la nueva institución emanaba del Ayuntamiento, puesto que las mismas personas que detentabañ el poder municipal aparecen al frente de ella. Ahora bien, la estrecha dependencia de la Junta municipal con la Contaduría Provincial presidida por el Intendente, que, a su vez, estaba sujeta a la Contaduria General, posibilitaba que este organismo se conformara como una entidad propia, paralela e independiente del Cabildo.

En la base de este planteamiento figuran especificadas - en el Real Decreto de 1760 - las atribuciones y funcionamiento de la Junta:

"Estas Juntas... han de examinar si los arbitrios que mas gravan al Pueblo, se pueden subrogar en otros mas tolerables y representarlo al Intendente para que si lo estima conveniente, lo haga presente al Consejo, quien consultara a S. M. por la via de Hacienda, y comunicara las resoluciones que S. M. sirva tomar al Intendente, para que lo haga saber a las Juntas para su cumplimiento...." (43).

Era, por tanto, la Junta local la que tenía sobre sí la responsabilidad del buen gobierno económico del municipio. Responsabilidad ésta que se constituía como privativa. La política de Esquilache de favorecer a las Intendencias se plasma en el Real Decreto, al considerar al Intendente como el punto de enlace entre las Juntas Municipales y el Consejo de Castilla, aproximándose, así, al modelo francés de Intendencias, como el más beneficioso para desarrollar el centralismo monárquico.

Buena prueba de que el nuevo organismo se estaba conformando como un ente autónomo, con atribuciones propias, y dependiente del Estado Absoluto, lo constituye el acta capitular de 24 de mayo de 1764, en la que se concedio facultad al procurador síndico para que procediera a la extinción de la Junta formada en la ciudad. Para justificar semejante actuación el Cabildo esgrimia aquellas disposiciones reales por las que las cuentas de propios y arbitrios debían pasar por los Ayuntamientos y procuradores 
síndicos "para que puedan adicionar y exponer lo que le pareciese» (44). Por ese procedimiento, el cuerpo de capitulares deshizo la citada institución, puesto que las atribuciones que se le conferían a ésta ya eran practicadas por el Concejo. El municipio utilizaba como arma su situación de privilegio ante la actitud reglamentista desarrollada por la Corona y protagonizaba el último y desesperado intento de recuperar sus facultades en el manejo y distribución de las arcas locales.

Mediante una Real Orden de 23 de noviembre de 1764, y otra posterior de 19 de julio de 1765, por haber sido desoida la primera, se instaba a la ciudad a la pronta reimplantación del organismo mandando enérgicamente

«... el Ayuntamiento de essa Ciudad se abstuviese, y no se mesclase en la Administracion y distribucion de dichos efectos, por no corresponderle de ningun modo, ni à sus Capitulares conocimiento alguno, vaxo del apercibimiento de que assi estos como el citado Thesorero serian responsables con sus Propios y Bienes à la reintegracion de las cantidades que librasen, aunque fuesen para gastos legitimos” (45).

No obstante, las intromisiones de los regidores no fueron radicalmente suprimidas. Testimonio de ello es que en el nuevo Reglamento dictado por Carlos III para la ciudad, en el año de 1767, se insistía en el mismo punto:

"Con el apercibimiento a los Capitulares del Ayuntamiento que si intentasen perturbar e impedir la ejecucion y observancia de este Reglamento se tomaran medidas de escarmiento cesando al Ayuntamiento...."(46).

Si bien con la implantación del nuevo organismo se colmaba uno de los principales anhelos de la Monarquia - tener la posibilidad de controlar directamente los fondos públicos de los municipios-, de hecho esta medida no tuvo las repercusiones inmediatas que se deseaban. Aun a pesar de que las cuentas locales debian remitirse anualmente a la Contaduria General, a través de las respectivas Intendencias, la prontitud con que debian presentarse en el órgano central distaba mucho en la realidad. Una carta del Intendente al corregidor de Alicante manifestaba con estas palabras la difícil situación:

"... el notable descuido de los Pueblos de esa Governacion en ordenar y remitirme annualmente las Cuentas de sus Propios y Arbitrios hà llegado à tal exceso que ya no admite disimulon(47).

Los intereses de la oligarquía municipal estaban, de nuevo, en la Junta. Obviamente, ésta no podia ni iba a proceder contra sus homónimos detentadores del régimen local. 
¿Qué conclusiones cabe apuntar de todo lo dicho? Resulta una pregunta obligada, pero, al mismo tiempo, dificil de contestar. En muchos casos, los resultados que pueden extraerse de este tipo de estudios son susceptibles de caer en visiones puramente localistas. Aun a riesgo de tropezar con semejantes escollos y a pesar de la falta de estudios y monografías especificas sobre el tema, que contribuyan al total esclarecimiento del régimen municipal español en el siglo XVIII, hemos pretendido sintetizar en grandes líneas la actuación del Estado sobre uno de los aspectos más sobresalientes del régimen local como son los propios y arbitrios.

Merece la pena resaltar que el ansia reformista de la Corona aparece perfilada a lo largo de la centuria. Ya hemos visto que Felipe $V$ aprovechó la oportunidad que se le brindaba con el desarrollo de la Guerra de Sucesión, al rectificar el rumbo de la organización municipal e intervenir en los asuntos económicos del municipio; igualmente, la actitud de Fernando VI se centró en frenar los abusos y corrupciones imperantes en los Ayuntamientos, dotando a la ciudad de nuevas ordenanzas; mientras que la intervención regia alcanzó sus cotas más altas, en 1760, con la creación de la Contaduría General y la implantación de las Juntas municipales.

Ahora bien, si estos cambios se sucedieron, hay que preguntarse hasta qué punto incidieron de forma dinámica en la sociedad del Antiguo Régimen. En primer lugar, el éxito de estas reformas se saldó en Alicante de forma parcial, principalmente, porque tales cambios no fueron todo lo profundos que se necesitaba para subvertir los cimientos sociales de la época.

Las medidas reformistas emprendidas con la abolición de la tasa de granos y la supresión de algunos arbitrios, resultaron propicias al libre comercio y debieron favorecer, por tanto, a la burguesía alicantina. Sin embargo, no se propugnó, en ningún momento, un reparto más equitativo de la carga fiscal, sino que se preservaban los supuestos sociales y económicos que sustentaban el panorama fiscal vigente. Si a ello unimos la pervivencia y no cuestionabilidad de un importante grupo de tributos concejiles, se evidencia, en suma, la diversidad fiscal característica del Antiguo Régimen y, por consiguiente, la pluralidad de intereses contrapuestos.

De la misma forma, aquellos intentos que pretendían frenar las tendencias nobiliarias en auge no dieron los frutos que se esperaban. Para ello hubiera sido necesario poner en tela de juicio los fundamentos económico-sociales del Estado Absoluto y atacar, así, la raíz del problema.

Con todo, el municipio borbónico permite deducir un hecho innegable. El absolutismo y la centralización figuran como los intrumentos más idó- 
neos para la consolidación del Estado, que pretende constituirse como soberano absoluto, y cuya soberania no era, en modo alguno, total. Urgia, pues, la necesidad de una instancia de poder politico que alcanzara a todos los reinos de la Monarquía. En esta panorámica, el municipio del Antiguo Régimen resulta, obviamente, una baza que debia ser jugada.

\section{NOTAS:}

(1) Archivo Municipal de Alicante (en adelante, A. M. A.). Memorial de la ciudad de Alicante a S. M. Felipe $V$ sobre los propios y arbitrios que goza la ciudad y lo ineludible de la restitución de sus derechos maritimos. (Impreso sin fecha). Arm. 5, Lib. 62, ff. 22-37.

(2) A. M. A. Libro de los arrendamientos. Arm. 17, sin catalogar.

(3) A. M. A. Indice de remisiones (años de 1701 a 1767).

(4) En 1767, las rentas de propios - heredad de Valladolid, almacén de entremuro y Casahospital nuevo- ascendian a 673 libras, 18 sueldos, 11 dineros, situándose alrededor de un seis por ciento del total de los ingresos locales A. M. A.

Ordenes de propios y arbitrios tocante a la muy ilustre ciudad de Alicante desde el año de 1767 en adelante. Arm. 13, Lib. 2, ff. 18-47.

(5) La mayoria de las contribuciones municipales alicantinas remontaban su origen a la época foral. Concretamente, las autoridades locales pretendian legitimar su pervivencia en el Setecientos mediante un Real Privilegio de 1371, dictado por Pedro IV de Aragón, quien concedió a Alicante la facultad de poder imponer sisas sobre los comestibles. A. M. A. Informe presentado en Cabildo para examinar la facuitad real de los distintos arbitrios municipales. Cabildos. Arm. 9, Lib. 57, Acta Capitular de 20 de diciembre de 1766.

(6) A. M. A. Estatutos para el gobierno de la ciudad de Alicante concedidos por Carlos // en 1699. (Impreso). Arm. 5, Lib. 62.

(7) A. M. A. Libre d'Establiments i Privilegis, Constitucions, i Reals Sentencies del Magnifich Mustassaf de la ciudad d'Alacant. Arm. 5, Lib. 53.

(8) GIMENEZ LOPEZ, E. Alicante en el siglo XVIII. Economia de una ciudad portuaria en el Antiguo Régimen. Institució Alfons el Magnánim. Diputació Provincial de València. Valencia, 1981 , p. 213.

(9) Este proceso no sólo afectó a la ciudad de Alicante. En Valencia fueron enajenados, igualmente, una serie de oficios menores. Vid. PALOP RAMOS, J. M.: "Centralismo borbónico y reivindicaciones económicas en la Valencia del Setecientos. El caso de 1760", en Estudis, número 4 (Valencia, 1975), pp. 196-199.

(10) GIMENEZ LOPEZ, E. Alicante..., p. 213.

(11) La ciudad entró en negociaciones directas con el entonces titular del empleo, al cual se le ofreció, además de la cantidad satisfecha a la Corona, 6.000 reales complementarios. Vid. GIMENEZ LOPEZ, E. Alicante..., p. 213. Valencia utilizó también este sistema en la segunda mitad de la centuria. Vid. PALOP RAMOS, J. M., Op. cit.

(12) GIMENEZ LOPEZ, E. Alicante..., pp. 213-214.

(13) A. M. A. Libro de los Arrendamientos. Arm. 17, sin catalogar.

(14) En la media pipa la medida era de 25 cántaros, mientras que en la pipa se traducía en 50. A. M. A. Ibídem. 
(15) GIMENEZ LOPEZ, E. Alicante..., p. 215.

(16) A. M. A. Ibidem.

(17) A. M. A. Nuevo Reglamento de S. M. Fernando VI concedido a la ciudad de Alicante, expedido por la via del Excm. Sr. Marqués de la Ensenada. (Impreso), Arm. 5, Lib. 62, ff. 495-510.

(18) A. M. A. Memorial de la ciudad de Alicante a S. M. Felipe V sobre los propios y arbitrios que goza la ciudad y lo ineludible de la restitución de sus derechos marítimos. (Impreso sin fecha). Arm. 5, Lib. 62, ff. 22-37.

(19) Sobre el particular Vid.: GIMENEZ LOPEZ, E. «La acción política del humanista Felipe Bolifón en Mayans y la llustración. Simposio Internacional en el Bicentenario de la muerte de Gregorio Mayans. Tomo II, Valencia, 1981, pp.613-627, y SAIZ PASTOR, C.: Abastecimiento y Hacienda municipal... pp. 54-69.

(20) A. M. A. Cabildos. Arm. 9, años 1736-1737.

(21) A. M. A. Nuevo Reglamento de S. M. Fernando VI concedido a la ciudad de Alicante, y expedido por la via del Marqués de la Ensenada. Arm. 5, Lib. 62, ff. 495-510.

(22) A. M. A. Libro de órdenes de Propios y Arbitrios de la ciudad de Alicante desde el año 1760 hasta el de 1767. Arm. 13, Lib. 1, ff. 168-169.

(23) A. M. A. Cabildos. Arm. 9, Actas Capitulares de 11 de julio, 18 de agosto y 20 de diciembre de 1766.

(24) A. M. A. Nuevo Reg/amento concedido por S. M. Carlos III. Arm. 13, Lib. 2, ff. 18-47.

(25) A. M. A. Libro de Correspondencia de la Junta de Propios y Arbitros. Arm. 13, s. n., ff. 374-386.

(26) A. M. A. Libro de los arrendamientos. Arm. 17, sin catalogar.

(27) A. M. A. Ibídem.

(28) A. M. A. Privilegios y provisiones Reales. Arm. 1, Lib. 61, f. 53.

(29) A. M. A. Libro de arrendamientos y fianzas. Arm. 8, Libs, 45, 46, 47 y 48.

(30) RUIZ TORRES, P. Señores y Propietarios. Institució Alfons El Magnánim. Diputació Provincial de Valencia. Valencia, 1981, p. 252.

(31) VIDAL OLIVARES, J. "Algunos aspectos de la vida económica y social de la ciudad de Alicante en las postrimerias del siglo XIX. 1887-1905». En Actes del / Congrès d'Estudis del Camp d'Alacant. (En prensa).

(32) En Castilla estos casos eran particularmente escandalosos. Vid. GONZALEZ ALONSO, B. Sobre el Estado y la Administración de la Corona de Castilla en el Antiguo Régimen. Siglo XXI, Madrid, 1981, p. 214.

(33) A. M. A. Nuevo Reglamento de S. M. Fernando VI concedido a la ciudad de Alicante por la vía del Excmo. Sr. Marqués de la Ensenada. (Impreso). Arm. 5, Lib. 62, ff. 495-510.

(34) Sobre el particular, vid. CLAVERO, B. El Código y el fuero. De la cuestión regional en la España contemporánea. Siglo XXI, Madrid, 1982, pp. 53-65.

(35) A. M. A. Ibidem.

(36) A. M. A. Ibidem.

(37) A. M. A. Ibidem.

(38) A. M. A. Ibidem.

(39) A. M. A. Ordenes de Propios y Arbitrios, tocante a la Muy llustre Ciudad de Alicante, desde el año de 1760, hasta el de 1767. Arm. 13, Lib. 1, ff. 182-184.

(40) A. M. A. Ibidem, ff. 204-209.

(41) ESCARTIN, F. "Aspectos de la administración provincial española bajo el Marqués de 
Esquilache. La respuesta del Intendente Contamina sobre la provincia de Cataluñan. En Historia social de la administración española. Barcelona 1980, pp. 269-286.

(42) A. M. A. Ibidem.

(43) A. M. A. Ordenanzas del establecimiento de las Contadurias de Propios y Arbitrios, y forma de dar las Cuentas de los productos. Arm. 5, Lib. 68, ff. 210-220.

(44) A. M. A. Ordenes de Propios y Arbitrios. Arm. 13, Lib. 1, ff. 165-167.

(45) A. M. A. Ibidem, ff. 177-179.

(46) A. M. A. Nuevo Reglamento concedido a la ciudad de Alicante por S. M. Carlos III. Arm. 13, Lib. 2, ff. 18-47.

(47) A. M. A. Carta fechada el 7 de diciembre de 1765. Arm. 13, Lib. 1, ff. 196-198. Más noticias encontramos en ff. 163-164 y 279-280. También en el Lib. 2, ff. 84-87. 